\title{
A Big Picture of Dynamic Capabilities
}

\author{
Eman Yassien \\ Dept. of Information Technology Management, WISE University \\ Amman, Jordan \\ Tel: 96-279-763-4025Ｅ-mail: eman.yassien@gmail.com
}

$\begin{array}{lr}\text { Received: July 14, } 2015 & \text { Accepted: August 18, } 2015 \quad \text { Published: October 1, } 2015 \\ \text { doi:10.5296/jmr.v7i5.8007 } & \text { URL: http://dx.doi.org/10.5296/jmr.v7i5.8007 }\end{array}$

\begin{abstract}
This paper discusses Dynamic Capabilities (DC) models presented in some earlier previous studies. The author shows that there are many fundamental and good thoughts that need to be organized and clearly specified in a full and comprehensive framework. The paper contributes by introducing a new framework for DC using an updated set of components. Also this paper provides another model that reflects DC from higher level perspective, whereas other issues such as strategic alignment and leadership are clearly included. The paper also contributes by provision of the whole understandable process of how DC can be formed.
\end{abstract}

Keywords: Dynamic Capabilities, Operationalize, competitive advantage, strategic, business, Absorbing Capability. 


\section{Introduction}

Business is full of many well-known examples of firms that accumulate valuable technological resources in order to strengthen their organizational capabilities such as IBM, Phillips and Microsoft. (Teece \& Pisano, 2004)

The importance of building organizational capabilities and owing valuable resources had been confirmed in some previous studies such as (Lado \& Wilson, 1994; Leopez-Cabrales, 2006; Newbert, 2008; Song, Benedelto \& Nason, 2007). however, they have discussed that sustaining certain organizational capabilities and building such valuable resources are not enough to sustain the competitive advantage and stay strong in business. (Teece \& Pisano, 2004)

Another source of useful capabilities is needed to be in line with the accelerated pace of innovation and the fervent competition. Organizations need to own capacities to integrate, build, and reconfigure internal and external competencies to address and shape rapidly changing business environments, which is the definition of Dynamic Capabilities (DC) (Teece et al., 1997)

Organization must develop its organizational capabilities, and then develop a capability to renew its competencies in order to respond to the continuous change in business environment. Teece et al (1997) believe that DC explains why some firms are more successful than others.

Dynamic Capabilities (DC) researches present one of the most attractive clashes that currently hits management field. (Di Stefano, Peteraf, \& Verona, 2010; Di Stefano, Peteraf, \& Verona, 2014)

Several perspectives are being discussed and many opinions are being proposed in order to deliver the newly born area of knowledge. The new discipline is still starving for agreed upon theory to set the basis / foundation for DC.

The following section sets the stage. Section 3 reviews main concepts in DC literature. Section 4 contributes by providing a new framework and model for DC. Finally section 5 presents the conclusion.

\section{Setting the Stage}

Since Teece \& Pisano light the spark of DC in their seminal article (Teece \& Pisano, 1994), it had attracted increasing attention from many scholars. Barreto (2010), for example, counts at least 1,534 articles in ABI/INFORM database use DC as the main concept from 1997 to 2007. The topic is a rich area for researches where many issues still need to be discussed.

Many authors (Zahra, Sapienza \& Davidsson, 2006; Barret, 2010; Di Stefano, Peteraf \& Verona, 2010; Di Stefano, Peteraf, \& Verona, 2014) exerted appreciated efforts to build on Teece \& Pisano (1994) seminal work. Some efforts opened other directions in the area such as Eisenhardt, and Martin (2000) who showed DC from organizational theory perspective whereas they analyze the processes support DC.

Arend \& Bromiley (2009) rejected the existence of this whole knowledge area entirely claiming that it does not present a quick "theoretical foundation", but Arend \& Bromiley's ideas were rejected strongly by many researchers. (Helfat \& Peteraf, 2009) 


\section{Macrothink}

Journal of Management Research

ISSN 1941-899X

2015, Vol. 7, No. 5

After all, it's natural that emerging theories develop slowly and that big ideas often take time to form (Williamson, 1999); Taking the transaction cost economies theory as a clear example of a knowledge area that took 35 years and lots of work to be operationalized (Williamson, 1993)

DC is considered as extension of the Resource Based View (RBV) theory (Barreto, 2010), whereas RBV theory offers a logical explanation of why an organization can achieve a competitive advantage through acquiring strong and valuable set of resources and capabilities, but it does not explain how and why certain organizations keep and sustain these competitive advantage in dynamic environments while others do not, even when they own similar resources and capabilities. (Teece et al, 1997; Zahra et al, 2006)

Organizations need more than strong and valuable resources to stay in the market. They need to have the ability to change their own organizational capabilities to address the rapidly changing environment. That's where DC comes to the scene.

\section{Operationalizing DC}

Operationalization is the process used to test hypotheses of the concept that makes the concept empirically understood and measurable (Sekaran \& Bougie, 2013)

Operationalizing DC is one of the most controversial ideas whereas some scholars consider DC framework as tautological (Arend \& Bromiley, 2009) or hard to be measured (Williamson, 1999). Xiao et al (2008) discuss that most empirical studies are limited into case studies with minimum number of quantitative applied methods. Wang \& Ahmad (2007) agree with Xiao et al (2008) and see that quantitative research is underdeveloped compared to qualitative research. Ambrosini \& Bowman (2009) argue that the discussion on DC is mainly conceptual.

Although the above common ideas were relatively inaccurate (Erikson, 2013), but, to some extent, they blocked the development of the theory's application.

Erikson (2013) refutes the previous discussion by collecting some previous studies for the peer-reviewed articles that were published till the end of 2009 . He counted 373 related articles, third of them were conceptual and 142 were empirical.

On contrary of what's often said (Wang \& Ahmad, 2007), the review finds fairly equal number of qualitative and quantitative studies. The study counted 71 qualitative papers, 59 quantitative papers and 12 mixed methods as shown in figure 1. 


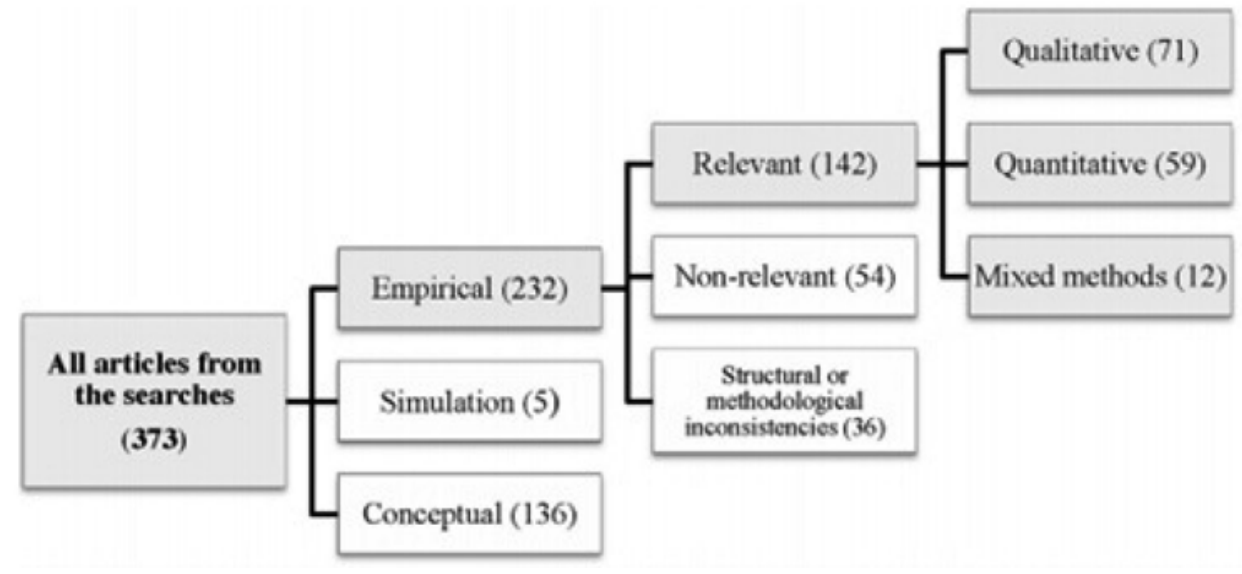

Figure 1. Selection of reviewed articles by Erikson (2014)

Erikson (2013) concludes that DC research comprises a well-balanced mix of qualitative and quantitative approaches. Teece (2014) supports Erikson's results in which he provides several supportive examples of strong empirical studies using questionnaires or in-depth case studies. Finally, undoubtedly the concept is sophisticated testing it is challenging.

The author agrees with Teece \& Erikson that although DC is a comprehensive topic but can be measured and can be studied empirically.

TQM (Total Quality Management) is a very similar interesting knowledge area that share both comprehensiveness and depth with DC. TQM is very inclusive, that it includes every person in the organization, with a more emphasis on the role of management to build and share the required vision and culture all over the organization.

Quality term, just as DC term, does not have a unified shared meaning of the concept. Such as DC, quality can have different perspectives, one of them even transcendental; impossible to communicate such as love and beauty. Other perspectives for quality relatively vary according to customer satisfaction, and even though, quality had been studied empirically (Okland, 2014; Conti, 2012), with a whole comprehensive management system, had been created to facilitate quality implementation.

In this paper, it is believed that DC concept compared to TQM can reflect an encouraging angle regarding DC operationalization.

Some researchers built their DC empirical study on the three fundamental processes of DC: integration capability, Learning capability and reconfiguration capability. Wu (2010), for example, performed an empirical study to examine the applicability of the resource-based view and DC view to environmental volatility. Wu used three items to measure DC: Resource integration capability, Learning capability and Resource reconfiguration capability, in which he collected responses from 253 Taiwanese firms. Wu's study finds that the explanatory power of DC exceeds that of resource based view in unstable environments. Firms that possess DC can effectively enhance their competitive advantages, despite facing highly unstable environments. 
Despite the importance of such study that favors the DC view, which is originally been emerged from RB theory, Wu believes that measuring DC processes is not sufficient to reflect the real DC, moreover the chosen scale for these processes is not accurate (Resource integration capability is questioned as insufficient-sufficient, Learning capability as slow-fast and Resource reconfiguration capability as insufficient-sufficient)

Protogerou, Caloghirou and Lioukas (2012) study the impact of DC on firm performance. This paper distinguishes three dimensions: coordinating/integrating activities, learning and strategic competitive response processes. It is suggested by Protogerou et al (2012) that these constitute distinct drivers that lead to the development of new configurations of functional competences.

Again the author believes that measuring DC processes is not sufficient to reflect the real DC impact.

Drnevichn \& Kriauciunas (2011) measured the variable (DC) using four items from the survey designed to measure the respondent's perception of how the firm used IT to enable new capabilities. These items were derived based on past researches by focusing on how a capability helps the firm create value through enabling new -capabilities.

These items are: to develop new products or services; to implement new business processes; to create new customer relationships; and to change ways of doing business.

The author disagrees with Drnevich \& Kriauciunas. Developing new products or services, implementing new business processes, creating new customer relationships, and changing ways of doing business are not mainly DC, they are more as results of implementing DC in the organization, but they are not mainly DC. DC involves the power to sense, seize or reconfigure its internal competences.

Chang (2012) used the following components to measure DC: Market-oriented sensitivity, knowledge absorption, Social-networking capability and integrative ability to communicate and negotiate. Whereas the market-oriented sensitivity is considered by Chang as the ability to identify, discover, create and pursue opportunities in the environment. The ability to absorb knowledge is defined as the ability to recreate existing operational capabilities with new knowledge and to respond more efficiently to market changes than competitors by learning, renewing and creating products or processes

Social-networking capability is defined by Chang (2012) as "the ability to combine individual knowledge into the unit's new operational capabilities". And finally is the integrative ability to communicate and negotiate defined as "the ability to orchestrate and deploy tasks, resources, and activities in the new operational capabilities".

The paper reflects mainly certain aspect of DC such as sensing and, to a smaller extent, "Seizing" while it ignores others. There is nothing about "transforming" capabilities, which are the other vital element of DC as a basis for building a sustainable advantage.

Feiler \& Teece (2014) organize DC sight around three groups of activity: sensing, seizing and transforming, whereas the sensing involves gaining knowledge and making strategic 
decisions. Seizing involves organizing and develop organizational and ecosystem readiness to capture the opportunity. While Seizing focuses on capturing opportunity and mitigating risk. Whereas Transforming involves continuous alignment and realignment of resources.

Teece (2014) clarifiers (for applied purpose) that DC can be usefully broken down into three primary clusters: "(1) identification, development, co-development, and assessment of technological opportunities in relationship to customer needs (sensing); (2) mobilization of resources to address needs and opportunities, and to capture value from doing so (seizing); and (3) to continue the renewal (transforming)".

This paper believes that it is very important to sense changing values of the environmental variables, as a pre-step to seize opportunities. Seizing -According to Oxford Advance Learner's Dictionary- means take an opportunity eagerly and decisively (Hornby \& Wehmeier, 1995), but most of the time seizing follows shaping for the opportunity in order to seize. Shaping step is not included explicitly in Teece model, rather it is embedded in sensing. Therefore, this paper opposes merging shaping step with sensing, because it contradicts with the original meaning of the word sensing, so the naming does not reflect the real meaning of the capability. Also, merging two fundamental concepts into one will most likely ruin the application of one or both of them.

Moreover, the author believes that continuous renewal (transforming) does not say the whole story, neither does it provide a solid ground for study. There is still the resource of knowledge to be absorbed, leadership to be considered and strategy to be aligned with, which are mentioned but not clearly specified in the Teece(2014) study.

Wang and Ahmed (2007) contributed to the DC's theory by defining DC through three main components: adaptive capability, absorptive capability and innovative capability. Adaptive capability is defined as the firms' ability to find and use opportunities (Wang \& Ahmed, 2007). Absorptive capability is seen as the ability to identify and apply external information for commercial use. Innovative capability refers to a firms' ability to develop new products, processes and markets.

First of all, innovation capability either is considered as part of absorptive capability (Cohen \& Levinthal, 1990), or, at least Absorptive Capability is regarded as one of the most influential drivers of innovation (Fosfuri and Tribo', 2008; Zhou and Wu, 2010). Second, the model ignored many other important factors such as sensing and seizing, which are the core of DC, and highly needed to implement the DC.

Alinaghian (2012) shared similar DC dimensions of Teece (2014) and added the shaping dimension.

Alinaghian (2012) defined sensing as the ability to constantly identify, create, and anticipate social, technological, economic, environmental and political trends and network configuration trends to disseminate identified, created and anticipated trends across the firm and the ecosystem.

Shaping is the ability to constantly devise reasonable responses to the sensed trends through 
modifying the existing contexts and developing new ones for existing businesses, inter-firm and intra-firm configuration and routines. (Alinaghian, 2012)

Seizing refers to the ability to constantly prioritize and select shaped opportunities, and allocate resources to capture opportunities developed. Finally, transforming refers to the ability to constantly implement the seized opportunities.

\section{Research's DC framework}

Good thoughts need to be organized and clearly specified. This paper contributes by introducing a new framework for DC with an updated set of components as shown in Figure (2):

The new framework provides comprehensive and inclusive sequential steps for implementing DC.

The framework suggests that organizations go into two stages: Formulation stage and Development stage. First stage (Formulation stage) is concerned with formulating the competitive advantages. This can be done by focusing on absorbing knowledge and building absorptive capacity. Absorptive capacity leads to building VRIN resources which constitutes the organizational capabilities.

The cyclic model starts with Absorbing knowledge, because the author sees that an important pre-step before sensing must be added; which is absorbing knowledge; the organization cannot explain what it senses unless it has previous knowledge (Schumpeter, 1934; Drucker, 1985; Siegel \& Renko, 2012). With lack of related and concerned knowledge, threats and opportunities can be observed but not translated correctly. Absorbing knowledge means to identify organization-relevant external knowledge, integrate it with the internal knowledge, transform and innovate, then apply the new knowledge (Cohen and Levinthal, 1990; Lenart, 2014). Absorbing includes learning from the outside environment, integrating with the inside to innovate and apply the learned and innovated knowledge. So absorbing concerns both the inside and the outside knowledge.

Evidences that absorbing capabilities positively impact building VRIN resources from many facets are frequently available. (Bertrand \& Mol ,2013; Miguélez,\& Moreno ,2015; Young Wook Seo, Seong Wook Chae, Kun Chang Lee,2015; Aiqi Wu\& Hinrich Voss ,2015; Haro-Domínguez et al,2007) 


\section{MInstitute Macrothink}

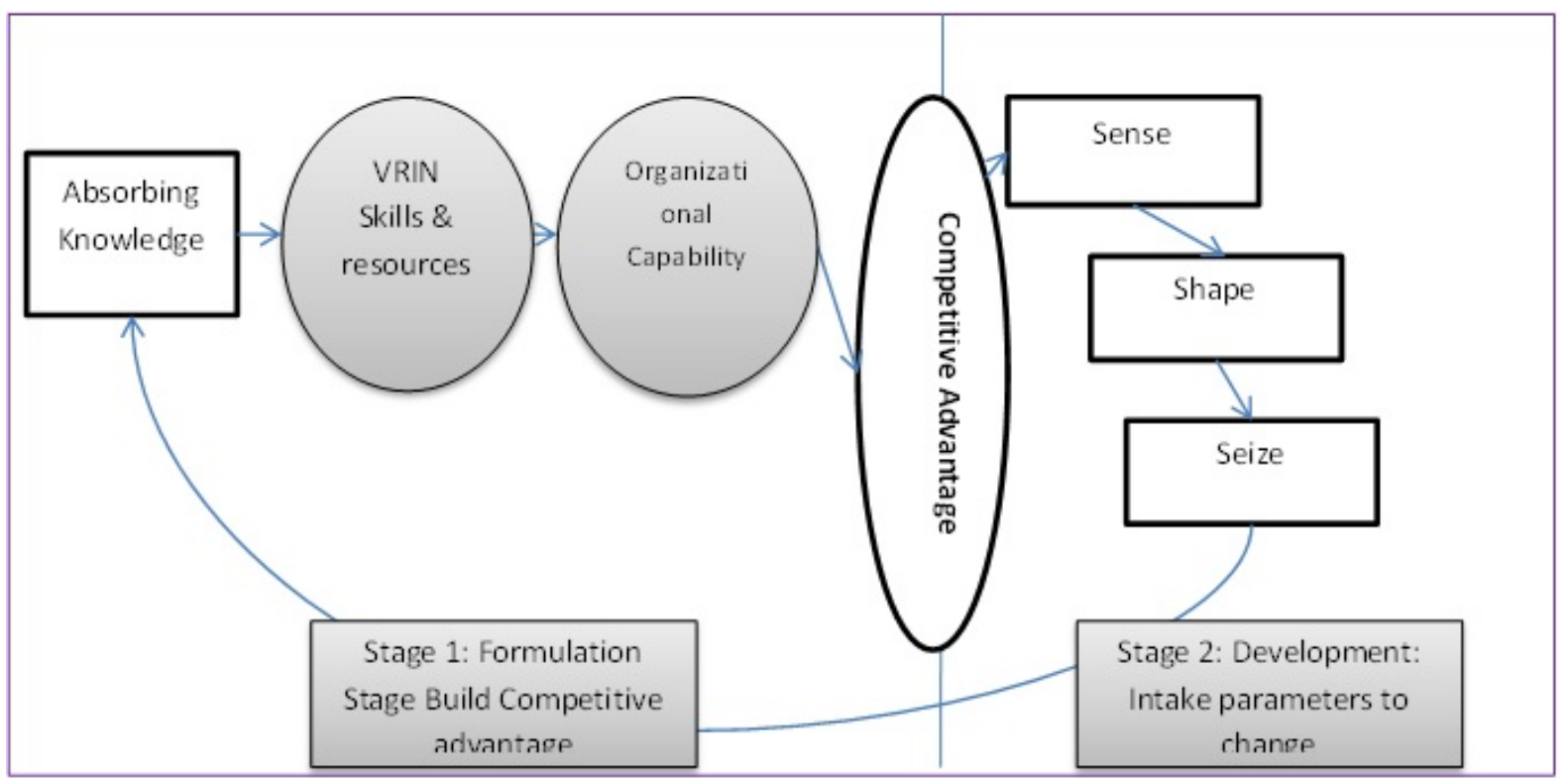

Figure 2. The New DC Model

VRIN resources according to the RBV, leads to building a strong organizational capability that contributes in building a strong competitive advantages (Wernerfelt, 1984; Rumelt, 1984; Penrose, 1959; Othman et al, 2015; Peteraf, 1993)

In order to sustain the acquired competitive advantages and keep up with the dynamic environment and its dynamic variables, organizations must build a set of capabilities and run bundle of activities that intake the variant environmental parameters and reconfigure accordingly. That's where we need the second stage. (Development Stage)

Second stage explains the way the organization can renew the formulated competitive advantage which was initially gained from the first stage, so that it will not get obsolete, this can be done by changing input parameters through DC activities which are: sensing, shaping, seizing.

During the three above activities (sensing, shaping, seizing) another new knowledge is being absorbed. This knowledge need to be internalized, processed, analyzed, transferred, integrated used and applied. All that can be done efficiently coming back to absorbing in the first stage. The model as explained indicates a cyclic nature.

DC involves more than specific and abstract combination of processes and rules, it has to do a lot with leadership and building culture \& management (Augier \& Teece, 2009; Teece, 2007, 2014). Eisenhardt and Martin's (2000) consider DC theory weak without "emotional inability to cope with uncertainty . . . in high-velocity markets" (2000, p. 1112) 


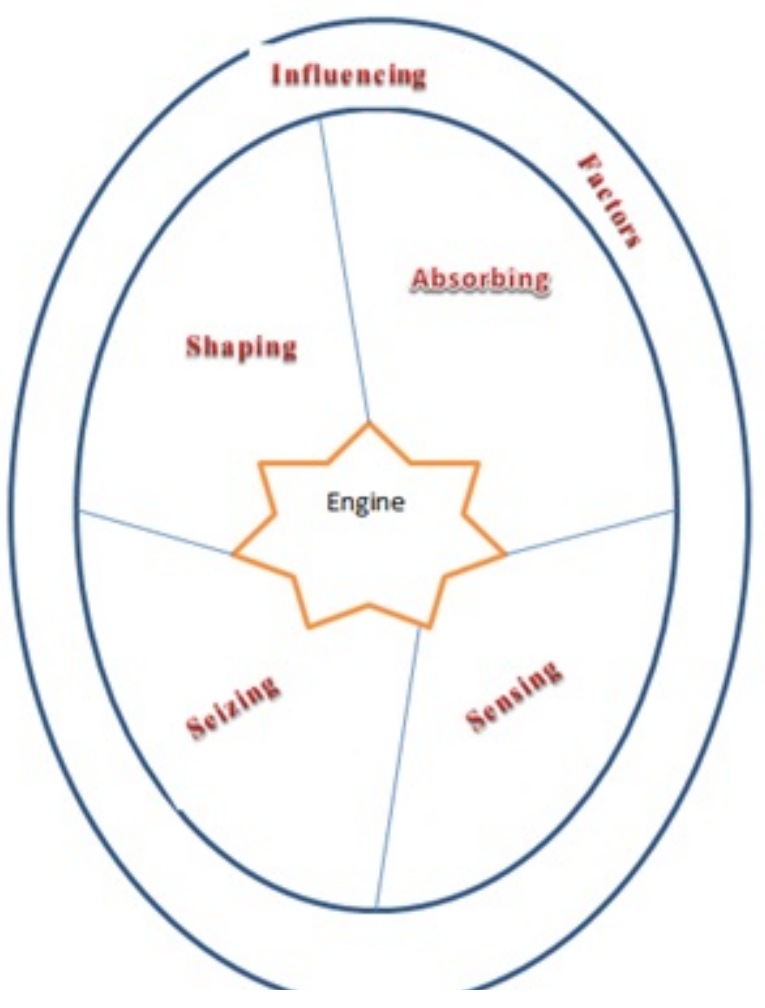

Figure 3.The Big Picture of the New Model

Strong Leadership matters to the organization's ability to carry on the needed continuous changes caused by dynamic activities in organizations to maintain the strength of DC existence. Moreover, DC activities (Absorbing, sensing, seizing and shaping) are mainly human actions (Teece, 2014) that must be led and managed considerably.

Add to that, that several studies relate Leadership and Culture to higher innovation level of the company (Koen et al, 2001). And as has been mentioned previously, innovation is one of the most important parts of absorptive capacity component.

Also, Eriksson (2014, p. 71) argued that the creation of DC's rests on internal and external antecedents. Internal antecedents on the structural, cultural and social levels are critical to influence the organization ability to develop and sustain DC's (Eriksson, 2014, p. 71).

Although several other researchers emphasize the role of leadership in DC success as critical (Galunic and Eisenhardt, 2001; Colbert, 2004; Knight and Cavusgil, 2004; Santos and Eisenhardt, 2005; Sapienza et al., 2006; Zahra et al., 2006) but it was never included in DC models.

For all what have been mentioned, the author suggests figure (3) as a high level scene for DC. The scene is derived from New Product Development Model (NPD) introduced as part of fuzzy front end concept by Koen et al (2002) 
The model in figure 3 considers leadership and culture as the engine. The engine in which provides leadership to fuel DC, and the culture in which it must operate. This study introduces leadership and management as the engine of implementing DC successfully. The engine, as shown in the figure 3 , at the center of the model, provides power for DC implementation.

The wheel, the inner part of the model, comprises the four activity elements of DC: Absorptive capacity, Sensing, Shaping and Seizing.

Because DC exists in an environment that consists of the corporation's business strategies, competitive factors, and the maturity of the technologies to be utilized, the model suggests a third wheel; the influencing factors.

The third wheel (the influencing factors) consists mainly of corporation and business strategy to ensure efficient flow of processes with value to the corporation and to keep DC activities aligned with the business. Sustained successful competitive advantage can only occur when the DC activities can be accomplished with alignment of organizational capabilities of the company.

Another influencing factor in the third wheel is the Outside World (i.e., distribution channels, customers and competitors), which all have high levels of effects on VRIN resources, organizational capabilities and eventually on the competitive advantages.

\section{Main Wheel (DC) Framework Components}

Absorbing Knowledge

Cohen and Levinthal (1990) defined organizational absorptive capacity as "an ability to recognize the value of new information, assimilate it and apply it to commercial ends".

Zahra and George (2002) proposed a more comprehensive concept of absorptive capacity involving: Acquisition, Assimilation, Transformation/internalization and Exploitation/application. Acquisition capability refers to a firm's capability to identify and acquire external knowledge that is important to the organization. Assimilation capability refers to a firm's capability to process, analyze, interpret and understand the information and knowledge acquired from the external sources. Transformation capability denotes a firm's capability to combine the acquired knowledge with the existing knowledge by adding knowledge, deleting knowledge or interpreting the same knowledge in different manner. Exploitation capability basically refers to the capability to apply the acquired or transformed knowledge into the operations.

For this study purpose, Absorbing Capability is defined as the ability to identify external knowledge, assimilate it with the internal knowledge, transform/internalize and apply/exploit external knowledge. (Cohen and Levinthal, 1990)

Keep in mind that learning is embedded in the absorbing process, where transformation/ internalization includes combining the acquired knowledge with the existing knowledge to come up with new knowledge. Thus, within this step, innovation happens (Cohen and 
Levinthal, 1990; Lenart, 2014; Lev et al, 2009).

Also within this step, transformation and reconfiguration that were earlier mentioned by Teece (2014) happens. Transforming that was defined by (Teece, 2014) Alinaghian (2012) as the ability to perform continuous alignment and realignment of tangible and intangible assets to constantly implement the seized opportunities, implementing opportunities. This happens during internalization process (Within absorbing knowledge stage) with the use of the absorbed knowledge from sensing, seizing and shaping.

Operationalize absorbing knowledge is widely studied in literature. Also clear identification of its components is available (Cohen and Levinthal, 1990; Lenart, 2014; Lev et al, 2009).

\section{Sensing}

Although Teece (2014), identified sensing as gaining knowledge about the external and internal environment and making decisions about strategic direction, the author believes that is not sensing, but rather gaining knowledge refers to the first dimension, which is absorbing as previously discussed.

Meanwhile this paper suggests another meaning of sensing, referring to Oxford definition of sensing (Hornby \& Wehmeier, 1995) "A faculty by which the body perceives an external stimulus; one of the faculties of sight, smell, hearing, taste, and touch". Another definition for sensing refers "to consciousness of stimulus or of a perception as pleasant or unpleasant".

This paper proposes a new definition of sensing which refers to the faculty by which the organization perceives an external or internal stimulus. Higher abilities to sensing means higher abilities to perceive and recognize stimulus as opportunities or threats. The new definition for sensing is closer to market-oriented sensitivity component defined by Chang (2012). Market-oriented sensitivity is the ability to identify, discover, create and pursue opportunities in the environment.

Thus, for this study, sensing is faculty by which the organization perceives an external or internal stimulus and translates it to opportunities or to face a threat.

\section{Shaping}

This paper agrees with Alinaghian (2012) that Shaping follows sensing whereas shaping is the ability to constantly formulate reasonable responses to the sensed opportunities through modifying existing contexts, developing and exploring new contexts for existing businesses.

Shaping to respond to the sensed opportunities and threat is a relative action depends on organizational strength and weaknesses.

So, identifying how to respond to the sensed opportunities can be done using SWOT analysis, which is used to generate business strategies and responses that use strengths and overcome weaknesses to take advantage of opportunities, and avoid threats.

\section{Seizing}

Teece (2014) sees seizing as mobilization of resources to address needs and opportunities, 
and to capture value.

Alinaghian (2012) defines seizing as the ability to constantly priorities and select shaped opportunities, and allocate resources to capture opportunities developed.

While Oxford definition of seize is to take opportunities eagerly and decisively, so this paper agrees with Alinaghian (2012) definition for seizing.

\section{Conclusion}

Work in DC area moved creatively and fast, but not well focused. The work need be seen as a whole understandable process that considers relationship with other issues such as the influencing factors. This paper provides a model that forms a starting point to see DC from higher level perspectives. The model still needs to be applied empirically.

\section{References}

Alinaghian, L. S. (2012). Operationalising dynamic capabilities: A supply network configuration approach. DRUID Academy, 1-45.

Ambrosini, V., \& Bowman, C. (2009). What are dynamic capabilities and are they a useful construct in strategic management? International Journal of Management Reviews, 11(1), 29-49. http://dx.doi.org/10.1111/j.1468-2370.2008.00251.x

Arend, R., \& Bromiley, P. (2009). Assessing the dynamic capabilities view: Spare change, everyone? Strategic Organization, 7(1), 75-90. http://dx.doi.org/10.1177/1476127008100132

Augier, M., \& Teece, D. J. (2009). Dynamic capabilities and the role of managers in business strategy and economic performance. Organization Science, 20(2), 410-421. http://dx.doi.org/10.1287/orsc.1090.0424

Barreto, I. (2010). Dynamic Capabilities: A Review of Past Research and an Agenda for the Future. Journal of Management, 36(1), 256-280. http://dx.doi.org/10.1177/0149206309350776

Bertrand, O., \& Mol, M. J. (2013). The antecedents and innovation effects of domestic and offshore R\&D outsourcing: The contingent impact of cognitive distance and absorptive capacity. Strategic Management Journal, 34(6), 751-760. http://dx.doi.org/10.1002/smj.2034

Chang, C. C. (2012). Exploring IT entrepreneurs' dynamic capabilities using Q-technique. Industrial Management \& Data Systems, 112(8), 1201-1216. http://dx.doi.org/10.1108/02635571211264627

Christensen, C. M., F. F. Suarez, \& J. M. Utterback. (1998). Strategies for survival in fast-changing industries. Management Sci. 44(12), 207-220. http://dx.doi.org/10.1287/mnsc.44.12.S207

Cohen, W.M., \& Levinthal, D.A. (1990), “Absorptive capacity: a new perspective on learning and innovation", Administrative Science Quarterly, 35, 128-52. http://dx.doi.org/10.2307/2393553 
Colbert, B. A. (2004). The complex resource-based view: Implications for theory and practice in strategic human resource management. Academy of Management Review, 29(3), 341-358.

Conti, T. (2012). Building total quality: a guide for management. Springer Science \& Business Media.

Cottrell, T., B. Nault. (2004). Product variety and firm survival in the microcomputer software industry. Strategic Management J., 25, 1005-1025 http://dx.doi.org/10.1002/smj.408

Di Stefano G, Peteraf M, \& Verona G. (2010). Dynamic capabilities deconstructed : A bibliographic investigation into the origins, development, and future directions of the research domain. Industrial and Corporate Change 19(4), 1187-1204. http://dx.doi.org/10.1093/icc/dtq027

Di Stefano, G., Peteraf, M., \& Verona, G. (2014). The Organizational Drivetrain: A Road To Integration Of Dynamic Capabilities Research. Academy Of Management Perspectives, 28(4), 307-327. http://dx.doi.org/10.5465/amp.2013.0100

Drnevich, PL, \& Kriauciunas, AP. (2011) Clarifying the conditions and limits of the contributions of ordinary and dynamic capabilities to relative firm performance. Strategic Management Journal, 32, 254-279 http://dx.doi.org/10.1002/smj.882

Drucker, P.F. (1985), Innovation and Entrepreneurship, Harper and Row, New York, NY

Eisenhardt, K. M., \& Martin, J. A. (2000). Dynamic capabilities: What are they? Strategic Management Journal, 21(10-11), 1105-1121.

Eriksson, T. (2013). Methodological issues in dynamic capabilities research - a critical review", Baltic Journal of Management, 8(3), 306-327 http://dx.doi.org/10.1108/BJOM-Jul-2011-0072

Eriksson, T. (2014). Processes, antecedents and outcomes of dynamic capabilities. Scandinavian Journal of Management, 30(1), 65-82. http://dx.doi.org/10.1016/j.scaman.2013.05.001

Feiler, P., \& Teece, D. (2014). Case study, dynamic capabilities and upstream strategy: Supermajor EXP. Energy Strategy Reviews, $\quad 3, \quad$ 14-20. http://dx.doi.org/10.1016/j.esr.2014.05.003

Fosfuri, A., \& Tribó, J. A. (2008). Exploring the antecedents of potential absorptive capacity and its impact on innovation performance. Omega, 36(2), 173-187 http://dx.doi.org/10.1016/j.omega.2006.06.012.

Galunic, D. C., \& Eisenhardt, K. M. (2001). Architectural innovation and modular corporate $\begin{array}{llll}\text { forms. Academy } \quad \text { of } \quad \text { Management journal, } & 44(6), & 1229-1249 .\end{array}$ http://dx.doi.org/10.2307/3069398

Haro-Dominguez, M. C., Arias-Aranda, D., Llorens-Montes, F. J., \& Ruiz-Moreno, A. (2007). The impact of absorptive capacity on technological acquisitions engineering consulting companies. Technovation, 27, 417-425. http://dx.doi.org/10.1016/j.technovation.2007.04.003 
Helfat C.E., \& Peteraf, M.A. (2009) Understanding dynamic capabilities: progress along a developmental path. Strat. Org., 7(1), 91-102. http://dx.doi.org/10.1177/1476127008100133

Hornby, A. S., \& Wehmeier, S. (1995). Oxford advanced learner's dictionary, 1430. Oxford: Oxford University Press.

Knight, G. A., \& Cavusgil, S. T. (2004). Innovation, organizational capabilities, and the born-global firm. Journal of International Business Studies, 35(2), 124-141. http://dx.doi.org/10.1057/palgrave.jibs. 8400071

Koen, P. A., Ajamian, G. M., Boyce, S., Clamen, A., Fisher, E., Fountoulakis, S., \& Seibert, R. (2002). Fuzzy front end: effective methods, tools, and techniques. Wiley, New York, NY.

Lado, A. and Wilson, M. (1994), Human resource systems and sustained competitive advantage: A competency based perspective, Academy of Management Review, 19, 699-727.

Lenart, R. (2014) Operationalization Of Absorptive Capacity. International Journal of Contemporary Management, 13(3), 86-98

Lev S, Fiegenbaum A, \& Shoham A. (2009) Managing absorptive capacity stocks to improve performance: Empirical evidence from the turbulent environment of Israeli hospitals. Eur Manag J., 27, 13-25

Lopez-Cabrales, A., Vale, R., \& Herrero, I. (2006). The Contribution of Core Employees to Organizational Capabilities and Efficiency, Human Resource Management, 45(1), 81-109. http://dx.doi.org/10.1002/hrm.20094

Miguélez, E., \& Moreno, R. (2015). Knowledge flows and the absorptive capacity of regions. Research Policy, 44(4), 833-848. http://dx.doi.org/10.1016/j.respol.2015.01.016

Newbert, S.L. (2007). Empirical research on the resource based view of the firm: an assessment and suggestions for future research. Strategic Management Journal, 28(2), 121-146. http://dx.doi.org/10.1002/smj.573

Oakland, J. S. (2014). Total quality management and operational excellence: text with cases. Routledge.

Othman, R., Arshad, R., Aris, N. A., \& Arif, S. M. M. (2015). Organizational Resources and Sustained Competitive Advantage of Cooperative Organizations in Malaysia. Procedia-Social and Behavioral Sciences, 170, 120-127. http://dx.doi.org/10.1016/j.sbspro.2015.01.021

Penrose, E. T. (1959). The Theory of Growth of the Firm, Basil Blackwell, London

Peteraf, M. A. (1993). The cornerstones of competitive advantage: a resource-based view. Strategic management journal, 14(3), 179-191. http://dx.doi.org/10.1002/smj.4250140303

Protogerou, A, Caloghirou, Y, \& Lioukas, S. (2012) Dynamic capabilities and their indirect impact on firm performance. Industrial and Corporate Change, 21, 615-647 http://dx.doi.org/10.1093/icc/dtr049

Rumelt, R. P. (1984). 'Toward a strategic theory of the firm'. In R. Lamb (ed.), Competitive 
Strategic Management, Prentice Hall, Englewood Cliffs, NJ, pp. 55\&570.

Santos, F. M., \& Eisenhardt, K. M. (2005). Organizational boundaries and theories of organization. Organization science, 16(5), 491-508. http://dx.doi.org/10.1287/orsc.1050.0152

Sapienza, H. J., Autio, E., George, G., \& Zahra, S. A. (2006). A capabilities perspective on the effects of early internationalization on firm survival and growth. Academy of management review, 31(4), 914-933. http://dx.doi.org/10.5465/AMR.2006.22527465

Siegel, D. S., \& Renko, M. (2012). The role of market and technological knowledge in recognizing entrepreneurial opportunities. Management Decision, 50(5), 797-816. http://dx.doi.org/10.1108/00251741211227500

Schumpeter, J.A. (1934). The Theory of Economic Development, Transaction Publishers, London.

Sekaran, U., \& Bougie, R (2013). Business Research Methods. sixth edition John Wiley \& Sons.

Seo, Y. W., Chae, S. W., \& Lee, K. C. (2015). The impact of absorptive capacity, exploration, and exploitation on individual creativity: Moderating effect of subjective well-being. Computers in Human Behavior, 42, 68-82. http://dx.doi.org/10.1016/j.chb.2014.03.031

Song, M.C., Benedetto, A. and Nason, R.W., (2007), Capabilities and Financial Performance; The Moderating Effect of Strategic Type, Journal of the Academy of Marking Science, 35, 18-34. http://dx.doi.org/10.1007/s11747-006-0005-1

Teece D J., \& Pisano G (1994). The Dynamic Capabilities of Enterprises: An Introduction. Industrial and Corporate Change, 3(3), 537-556.

Teece, D. J. (2007). Explicating dynamic capabilities: the nature and microfoundations of (sustainable) enterprise performance. Strategic Management Journal, 28(13), 19-50. http://dx.doi.org/10.1002/smj.640

Teece, D. J. (2014). The Foundations Of Enterprise Performance: Dynamic And Ordinary Capabilities In An (Economic) Theory Of Firms. Academy Of Management Perspectives, 28(4), 328-352. http://dx.doi.org/10.5465/Amp.2013.0116

Teece, D. J., G. Pisano, \& A. Shuen (1997). Dynamic capabilities and strategic management. Strategic Management Journal, 18(7), 537-533. http://dx.doi.org/10.1002/(SICI)1097-0266(199708)18:7<509::AID-SMJ882>3.0.CO;2-Z

Teece, D., \& Pisano, G. (2004). Chapter 42: The Dynamic Capabilities of Firms. In , Handbook on Knowledge Management 2: Knowledge Directions (pp. 195-213). Springer Science \& Business Media B.V. / Books. http://dx.doi.org/10.1002/(SICI)1097-0266(199708)18:7<509::AID-SMJ882>3.0.CO;2-Z

Wang, C. L., \& Ahmed, P. K. (2007). Dynamic capabilities: A review and research agenda. International Journal of Management Reviews, 1, 31-51. http://dx.doi.org/10.1111/j.1468-2370.2007.00201.x 
Wernerfelt, B. (1984). 'A resource based view of the firm', Strategic Management Journal, 5, 171-180. http://dx.doi.org/10.1002/smj.4250050207

Williamson, O.E. (1999). Strategy research: governance and competence perspectives. Strategic Management Journal, 1087-108. http://dx.doi.org/10.1002/(SICI)1097-0266(199912)20:12<1087::AID-SMJ71>3.0.CO;2-Z

Wu, A., \& Voss, H. (2015). When does absorptive capacity matter for international performance of firms? Evidence from China. International Business Review, 24(2), 344-351. http://dx.doi.org/10.1016/j.ibusrev.2014.08.006

Wu, L.y. (2010) Applicability of the resource-based and dynamic-capability views under environmental volatility. Journal of Business Research, 63(2010) 27-31. http://dx.doi.org/10.1016/j.jbusres.2009.01.007

Zahra S A, Sapienza H J., \& Davidsson P (2006). Entrepreneurship and Dynamic Capabilities: A Review, Model and Research Agenda. Journal of Management Studies, 43, 917-955. http://dx.doi.org/10.1111/j.1467-6486.2006.00616.x

Zahra, S.A. and George, G. (2002). Absorptive capacity: a review, reconceptualization, and extension. Academy of Management Review, 27(2), 185-203.

\section{Copyright Disclaimer}

Copyright for this article is retained by the author(s), with first publication rights granted to the journal.

This is an open-access article distributed under the terms and conditions of the Creative Commons Attribution license (http://creativecommons.org/licenses/by/3.0/). 